\title{
Healthy and Safety Workplace Design to Enhance Work Performance
}

\author{
L.Nurul Huda ${ }^{1}$ \\ ${ }^{1}$ Lecturer, Faculty of Engineering University of Sumatera Utara, Indonesia \\ listiani@usu.ac.id
}

\begin{abstract}
Healthy and safety workplace was studied in one of national crude palm oil plant that located at North Sumatera. There are existed problems such as many flakes of palm oil aorund the dolly, spilled a fresh fruit bunches around the loading ramp, slippery area around tipler and rel track caused by mixing of water and oil that spoilling from boiling etc. Therefor, there found a lot of unhealth and unsafe condition in workplace that can inlfuence to the worker performance. In this paper, the problems were investigated by 5-S method as one of ergonomic tool to improve the lean manufacturing. It applied the questionnaire semantic scale and the diagnosis result was drawn by a radar-map. The results shown that the poorest average of questionnaire diagnosis of Seiri/Sort is $\mathbf{- 1}$ located at Kernel Plant station (w/c-4), Seiton/Simplify is $-1,25$ located at Workshop station (w/c-7), Seiso/Sweep is -1,67 located at Tripler and Rel Track station (w/c2), Shitsuke/Standardize is -1,33 located at Tripler and Rel Track station (w/c-2) and Sheiketsu/Suistan is -1 located at Klarifikasi station (w/c-5). All of the radar-maps of 5-S diagnosis are not rose perfectly. These indicated that almost of work-center environment in the plant are very poor and should be improved. It perhaps can improve the healthy and safety of work and work performance of the worker.
\end{abstract}

Keywords — Lean Manufacturing, 5-S, Palm Oil Plant, Healthy, Safety

\section{INTRODUCTION}

The concept of Ergonomic in Lean Manufacturing can help manufacturing and industrial engineers maximum work output without physical harm to workers. Neat and orderly workplace will produce hygienic products. 5S method is based on the assumption that the organization, order, cleanliness, standardization and discipline in the workplace are essential conditions for the production of high quality products and services. It is characterized by little or no waste and high productivity [3].

The fifth component of the $5 \mathrm{~S}$ are seiri, seiton, seiso, seiketsu, shitsuke, and. Seiri stage aims to sort out between equipment used and unused. Seiton stage aims to organize equipment/goods so neat, seiso phase aims to identify the things related to the cleanliness of the plant, Seiketsu stage aims as consolidation, meaning if seiri and seiton, seiso already underway must be maintained the implementation that is already good and less good repair. The last stage is shitsuke which aimed to let workers understands the important of $5 \mathrm{~S}$ work attitude. It is really important to know which method can help to begin the process of continuous improvement in order to achieve increased productivity and safety of the workplace through participation and knowledge of the involved staff [1].

Point out the main misunderstandings and errors of Chinese enterprises in implementing $5 \mathrm{~S}$ via investigations in manufacturing enterprises. This resulted from the failure of $5 \mathrm{~S}$ management and proposed steps to carry out $5 \mathrm{~S}$ programmes successfully, namely how to make $5 \mathrm{~S}$ a culture [4].

In some countries, the implementation of $5 \mathrm{~S}$ methodology is a simple way to comply with the minimum requirements for health and safety in the workplace. This relationship has led to the possibility of extending the scope of the $5 \mathrm{~S}$ through the incorporation of a new S, 'safety and health' [2].

One of the factors supporting the increasing productivity of work is with a comfortable environment. Comfortable work environment will make employees work more effectively so that the target company has set work will be achieved even exceeding the target. Problems occurred in Crude Palm Oil Plant is the environment it works that have yet to implement $5 \mathrm{~S}$ method in production floor. In Crude Palm Oil Plant consists of eight departments are the department of loading ramp, tipler and rail track, pressing, kernel palnt, clarification, boiler, workshops, sorting. Workplace conditions in Crude Palm Oil Plant shows that the floor was dirty, oil spill on the floor and slippery floors, that cause floor cleaning becomes difficult and irregular production equipment and piled in the workers work area are 
shown in Figure 1. It thus makes working environment chaotic and disorganized.

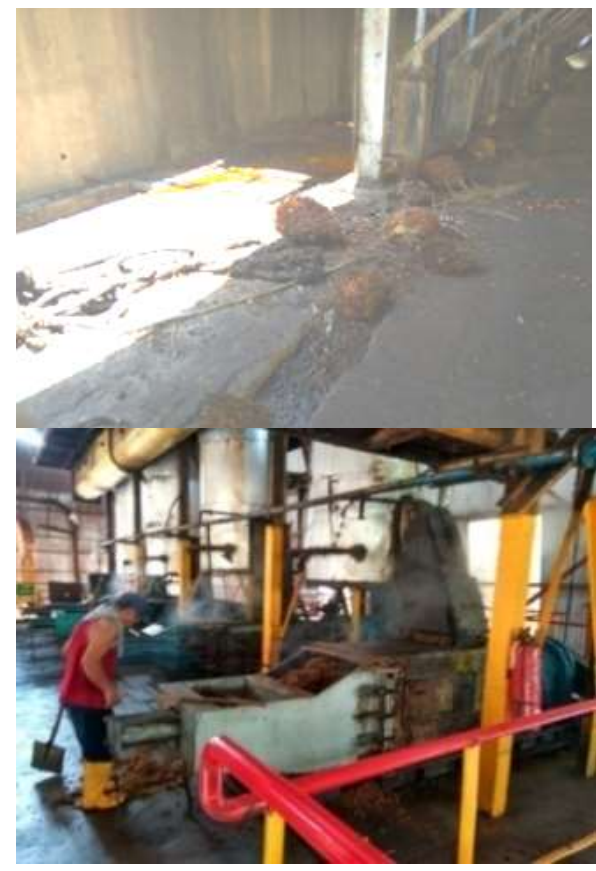

Fig. 1 Workplace of Crude Palm Oil Plant

Good Manufacturing Practice Standards is a guide how to produce food to produce good quality food related to nutritional content, health, and food safety are required as a condition for export can be met by creating a comfortable working environment in terms of rights and cleanliness.

\section{METHOD}

The study was conducted in shopfoor of crude palm oil production area. This study aims to improve the working area using 5-S concept as one tool in Lean Ergonomic.The problems of 8-work center (w/c) were investigated by 5-S method as one of ergonomic tool to improve the lean manufacturing. It applied the questionnaire semantic scale and the diagnosis result was drawn by a radar-map. The instrument used in this study was a 5-S questionnaire. Steps in data processing with the $5 \mathrm{~S}$ method shown as follow:

1) Identifying the problems that exist at each workstastion.

2) Base on the indicators of Seiri, Seiton, Seiso, Seishou, Seiketsu that developed by Panasonic Manufacturing, Indonesia the problems judged subjectively by subjects at each workstation. The subjective judgements were consists of several votes that describe at below.

3) The votes of each workstation of each $5 \mathrm{~S}$ components were diagnosed averagely by the worker at the workplace and it result are drawn in radar maps.
4) The pattern of radar maps evaluated according to the real problems at each workstation.

5) Improvement of each workstation have been carr aiedout ccording evaluation at poin 4 (the improvement is not explain in this paper)

The diagnosis of $5 \mathrm{~S}$ questionnaire consist of 20votes and each vote has 4-possible answer as follows :

1) Not good

2) Less good

3) Good

4) Very good

The votes in the $5 \mathrm{~S}$ questionnaire are dividing into each $5 \mathrm{~S}$ component as follows :

\section{A. Seiri is Sort}

First step in 5S, it refers to the sorting of the clutter from the other items within the work area that are actually needed. This stage requires the team to remove all items that clearly do not belong in the working area and only leave those that are required for the processes in question.

Step in applying seiri as follows :

Step 1: Remove unnecessary items and dispose of them properly.

Step 2: Make work easier by eliminating obstacles.

Step 3: Reduce chances of being disturbed with unnecessary items.

Step 4: Prevent accumulation of unnecessary items.

Step 5: Evaluate necessary items with regard to cost or other factors.

Step 6: Remove all parts or tools that are not in use.

Step 7: Segregate unwanted material from the workplace.

Step 8: Need fully skilled supervisor for checking on regular basis.

Step 9: Don't put unnecessary items at the workplace \& define a red-tagged area to keep those unnecessary items.

Step 10: Waste removal.

\section{B. Seiton is Set in Order}

Where or Straighten is the process of taking the required items that are remaining after the removal of clutter and arranging them in an efficient manner through the use of ergonomic principles and ensuring that every item "placing the item at its station".

Based on the observations, Palm products are not neatly arranged can be seen in Figure 2. 


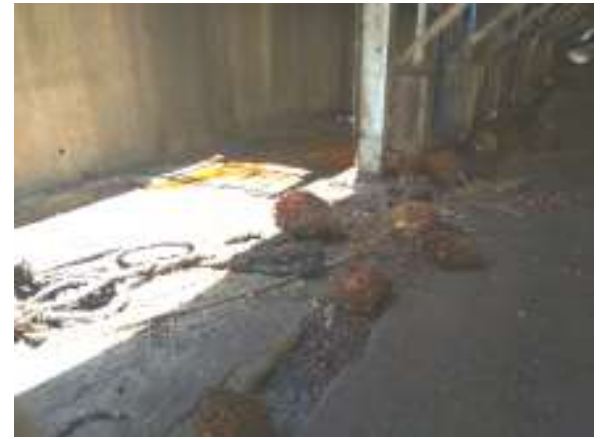

Fig. 2 Sorting Stations Condition that was not Tidy

\section{Seiso is Shine}

Which creates a clean working conditions and environment. Cleaning here is not just cleaning but also seen as a form of screening for treatment. Based on the observations, palm's scrap scattered on the floor area of the cutting station and the walls were dirty at every station is shown in Figure 3.

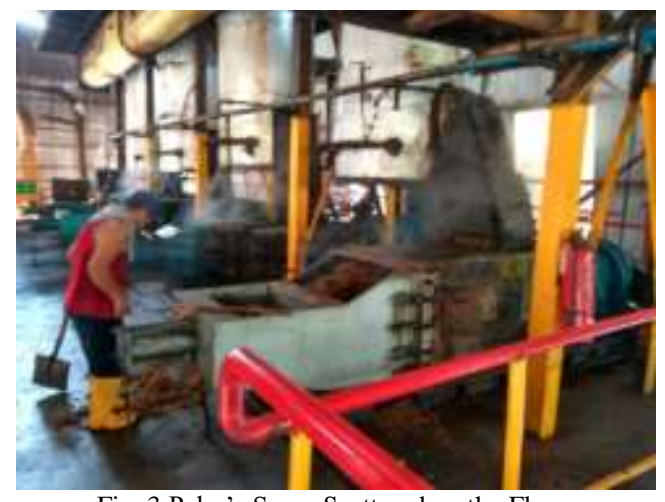

Fig. 3 Palm's Scrap Scattered on the Floor

Steps in applying Seiso:

Step 1: Determine what or where that will be cleared The area to be cleaned is the floor and walls of the station of palm's loading ramp and pressing

Step 2: Assign who is doing the cleanup activities The responsible worker for the cleanup palm's scrap is the worker who worked at the loading ramp station

Step 3: Determine the cleaning procedures of the working area

Clean-up is done every day.

Step 4: Provide the equipment used for cleanup The equipment will be used, namely brooms and mops.

Step 5: Start doing cleanup

\section{Seiketsu is Standardize}

The process of ensuring that what we have done within the first three stages of $5 \mathrm{~S}$ become standardized; that is we ensure that we have common standards and ways of working. Standard work is one of the most important principles of Lean manufacturing.

The Steps in applying Seiketsu as follows :

Step 1: Standardize the best practices in the work area.

Step 2: Maintain high standards in workplace organization at all times.

Step 3: Maintain orderliness. Maintain everything in order and according to its standard.

Step 4: Everything in its right place.

Step 5: Every process has a standard.

\section{E. Shitsuke is Sustain}

Ensuring that the company continue to continually improve using the previous stages of $5 \mathrm{~S}$, maintain housekeeping, and conduct audits and so forth. $5 \mathrm{~S}$ should become part of the culture of the business and the responsibility of everyone in the organization.

The Steps in applying Shitsuke as follows :

Step 1: Not Harmful to anyone

Step 2: Also translates as "do without being told".

Step 3: Perform regular audits.

Step 4: Training and discipline.

Step 5: Training is goal-oriented process. Its resulting feedback is necessary monthly.

\section{RESULTS AND DISCUSSIONS}

The results will be discussed in every part of $5 \mathrm{~s}$ method's.

\section{A. Seiri}

Recap of the questionnaire seiri diagnosis can be seen in Table 1.

TABLE I

RECAPITULATION SEIRI DiAgNOSIS

\begin{tabular}{|c|c|c|c|c|c|c|c|c|c|}
\hline \multicolumn{10}{|c|}{ Seiri } \\
\hline \multirow{2}{*}{$\begin{array}{l}\text { State- } \\
\text { ment }\end{array}$} & \multicolumn{8}{|c|}{ Station } & \multirow{2}{*}{$\begin{array}{l}\text { Ave } \\
\text { rage }\end{array}$} \\
\hline & 1 & 2 & 3 & 4 & 5 & 6 & 7 & 8 & \\
\hline 1 & 1,33 & 1 & 1 & -1 & 1,5 & 2 & $-0,5$ & $\begin{array}{c}- \\
1,33 \\
\end{array}$ & 0,5 \\
\hline 2 & 1,33 & 1,33 & 1,5 & 1,5 & 1,5 & 2 & 1,75 & 1,67 & 1,57 \\
\hline 3 & 1 & 1 & 2 & 1 & 2 & 1,5 & 1,75 & 1,67 & 1,46 \\
\hline 4 & 1,67 & 1 & 2 & 1 & 1,5 & 2 & 0 & 1,67 & 1,32 \\
\hline 5 & 1,67 & 1,67 & 1 & 1 & 2 & 1 & 1,25 & 1,33 & 1,36 \\
\hline 6 & 1,33 & 1,67 & 1,5 & 2 & 2 & 1 & 1,5 & 2 & 1,63 \\
\hline 7 & 2 & 2 & 1,5 & 2 & 1,5 & 1,5 & 1,5 & 2 & 1,75 \\
\hline 8 & 1 & -1 & -1 & 1 & 1 & 1,5 & 1,25 & 1,67 & 0,68 \\
\hline $\begin{array}{l}\text { Ava- } \\
\text { rage }\end{array}$ & 1,42 & 1,08 & 1,18 & 1,06 & 1,63 & 1,56 & 1,06 & 1,33 & \\
\hline
\end{tabular}


Seiri's radar map shown in Figure 4.

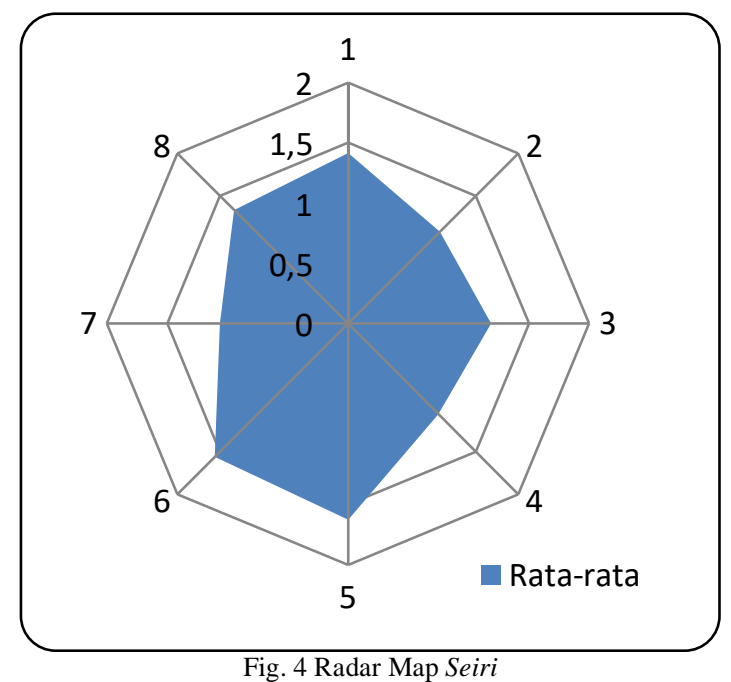

The figures showed that low for the station that is the fourth station (Kernel Plant) with a weight of-1 means that the most problematic if seen from the approach is kernel seiri plant that is characterized by the presence of goods that are not required in the workplace. This problem will cause the working environment at the production floor in kernel plant be more narrow than that should have such articles can still be moved.

\section{B. Seiton}

Recapitulation of the questionnaire Seiton diagnosis can be seen in Table II.

TABLE II

RECAPITULATION SEITON DIAGNOSIS

\begin{tabular}{|c|c|c|c|c|c|c|c|c|c|}
\hline \multicolumn{10}{|c|}{ Seiton } \\
\hline \multirow{2}{*}{$\begin{array}{l}\text { State- } \\
\text { ment }\end{array}$} & \multicolumn{8}{|c|}{ Station } & \multirow{2}{*}{$\begin{array}{l}\text { Ave- } \\
\text { rage }\end{array}$} \\
\hline & 1 & 2 & 3 & 4 & 5 & 6 & 7 & 8 & \\
\hline 1 & 1,67 & 1,33 & 2 & 1 & 2 & 2 & $-1,25$ & 1,33 & 1,26 \\
\hline 2 & 1,33 & 1,67 & 2 & 1,5 & 1,5 & 1,5 & 1,75 & 1,33 & 1,57 \\
\hline 3 & $\overline{1,33}$ & 2 & 2 & 1 & 1,5 & 1,5 & 1,5 & 1,67 & 1,23 \\
\hline 4 & 1,33 & 2 & 1,5 & 2 & -1 & 1,5 & 1,25 & 2 & 1,32 \\
\hline 5 & 1,33 & 1,33 & 1 & 2 & 1,5 & 1,5 & 1,5 & 1,67 & 1,48 \\
\hline 6 & $\begin{array}{l}- \\
1,67\end{array}$ & -1 & $-1,5$ & -1 & -2 & $-1,5$ & $-1,25$ & $\overline{1}-67$ & $\begin{array}{l}- \\
1,45\end{array}$ \\
\hline 7 & 1 & -1 & 1 & -1 & 1 & -1 & -1 & -1 & $\overline{0}, 25$ \\
\hline 8 & 2 & 1 & 1,5 & 1,5 & 2 & 2 & 2 & 1,67 & 1,71 \\
\hline $\begin{array}{l}\text { Ava- } \\
\text { rage }\end{array}$ & 0,71 & Iton & 1,19 & 0,88 & 0,81 & 0,94 & 0,56 & 0,88 & \\
\hline
\end{tabular}

Figure 5 shows the radar map of Seiton.

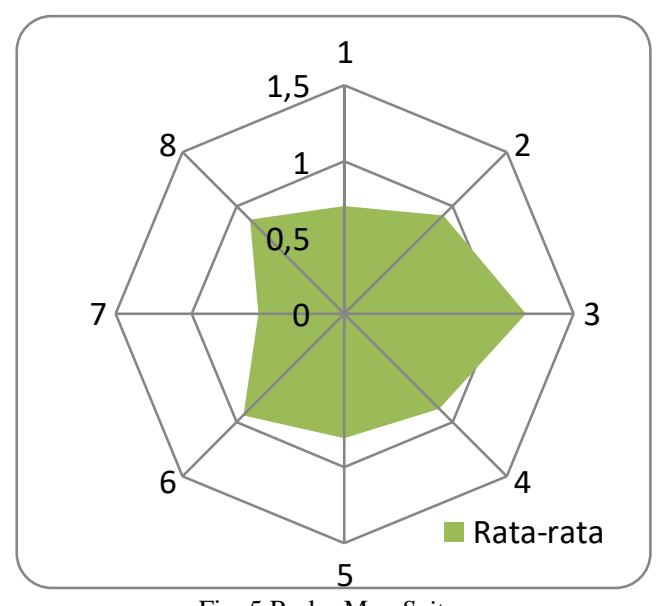

Fig. 5 Radar Map Seiton

The figures showed that low for the station that is the seventh station (Workshop) with weights-1.25 means the most problematic if seen from the approach of the workshop is seiton used equipment is not returned to the original place of capture and storage of equipment not supplied label. This problem will cause the production floor is irregular because the equipment will be mixed with other items. If there is a label on the storage of goods/equipment will further facilitate the storage of goods. This will help return the equipment used to place quickly.

C. Seiso

Recapitulation of the questionnaire Seiso diagnosis can be seen in Table III.

TABLE III

RECAPITULATION SEISO DiAgNOSIS

\begin{tabular}{|c|c|c|c|c|c|c|c|c|c|}
\hline \multicolumn{10}{|c|}{ Seiso } \\
\hline \multirow{2}{*}{$\begin{array}{l}\text { State- } \\
\text { ment }\end{array}$} & \multicolumn{8}{|c|}{ Station } & \multirow{2}{*}{$\begin{array}{l}\text { Ave- } \\
\text { rage }\end{array}$} \\
\hline & 1 & 2 & 3 & 4 & 5 & 6 & 7 & 8 & \\
\hline 1 & 1,33 & -1 & 1 & 1 & 1 & 1 & 1 & 1,33 & 0,83 \\
\hline 2 & 1,67 & $\begin{array}{l}- \\
1,67\end{array}$ & -1 & -1 & $-1,5$ & -2 & -1 & 1 & $-0,69$ \\
\hline 3 & 1 & $-\overline{1,33}$ & $-1,5$ & $-1,5$ & -1 & 1 & 1,5 & 1,67 & $-0,02$ \\
\hline 4 & $\overline{-}$ & -1 & $-1,5$ & -1 & -1 & -1 & 1,5 & 1,67 & $-0,46$ \\
\hline 5 & 2 & 1 & 1 & 1 & 1 & 1 & 1,25 & 2 & 1,28 \\
\hline 6 & 1,33 & $\begin{array}{l}- \\
1,67\end{array}$ & 1 & -1 & $-1,5$ & 1 & 1,75 & 1,33 & 0,28 \\
\hline 7 & $\begin{array}{l}- \\
1,67\end{array}$ & -1 & $-1,5$ & 1 & $-1,5$ & -2 & 1,25 & -1 & $-0,80$ \\
\hline 8 & 1 & -1 & 1,5 & 1,5 & 1,5 & 1 & 1,25 & 1 & 0,97 \\
\hline $\begin{array}{l}\text { Ava- } \\
\text { rage }\end{array}$ & 0,67 & $\begin{array}{l} \\
0,96\end{array}$ & $-\overline{0}, 13$ & 0 & $-0,38$ & 0 & 1,06 & 1,13 & \\
\hline
\end{tabular}


Seiso radar map is shown in Figure 6.

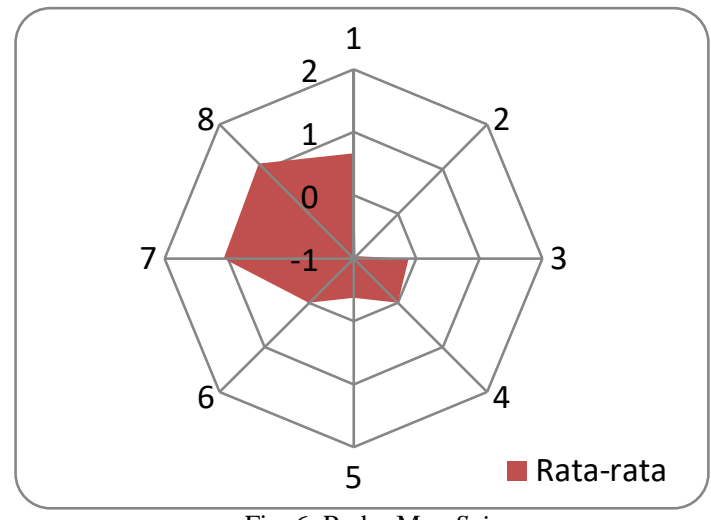

Fig. 6 Radar Map Seiso

The figures showed that second station (Tipler and rail Track) has low score with weights-1.67 means the most problematic if seen from the approach of seiso tipler and rail station are tracks where the existence of a puddle or a floor above the rest of the ingredients all areas that are difficult to clean. This problem will cause the production floor is dirty because of standing water that mixed with Palm oil and dust resulting in dirt on the floor.

\section{Seiketsu}

Recapitulation of the questionnaire Seiketsu diagnosis can be seen in Table IV.

TABLE IV

ReCaPitulation SeITSUKe Diagnosis

\begin{tabular}{|c|c|c|c|c|c|c|c|c|c|}
\hline \multicolumn{10}{|c|}{ Seiketsu } \\
\hline \multirow{2}{*}{$\begin{array}{l}\text { State- } \\
\text { ment }\end{array}$} & \multicolumn{8}{|c|}{ Station } & \multirow{2}{*}{$\begin{array}{l}\text { Ave- } \\
\text { rage }\end{array}$} \\
\hline & 1 & 2 & 3 & 4 & 5 & 6 & 7 & 8 & \\
\hline 1 & -1 & $\begin{array}{c}- \\
1,33\end{array}$ & 1 & 1 & -1 & -1 & 1,25 & 1,33 & 0,03 \\
\hline 2 & 1,67 & 1 & 1 & 1 & 1 & 2 & 1,25 & 1,67 & 1,32 \\
\hline 3 & 1 & 0,67 & 1,5 & 1 & 1,5 & 1 & 1,75 & 2 & 1,30 \\
\hline 4 & 1,33 & 1 & 1,5 & 1,5 & 1,5 & 1,5 & 1,75 & 1,33 & 1,43 \\
\hline 5 & 1,67 & -1 & 2 & -1 & 1,5 & 1 & 1,25 & 1,33 & 0,84 \\
\hline 6 & 1,67 & 1 & 2 & 1 & 0 & 1,5 & 1,25 & 2 & 1,30 \\
\hline 7 & 2 & 1,33 & 2 & 1 & 2 & 1,5 & 1,75 & 1,67 & 1,66 \\
\hline 8 & 2 & 1 & 1 & 1 & 1,5 & 1,5 & 1,75 & 1,67 & 1,43 \\
\hline $\begin{array}{l}\text { Ava- } \\
\text { rage }\end{array}$ & 1,29 & 0,46 & 1,5 & 0,81 & 1 & 1,12 & 1,5 & 1,63 & \\
\hline
\end{tabular}

Seiketsu radar map is shown in Figure 7.

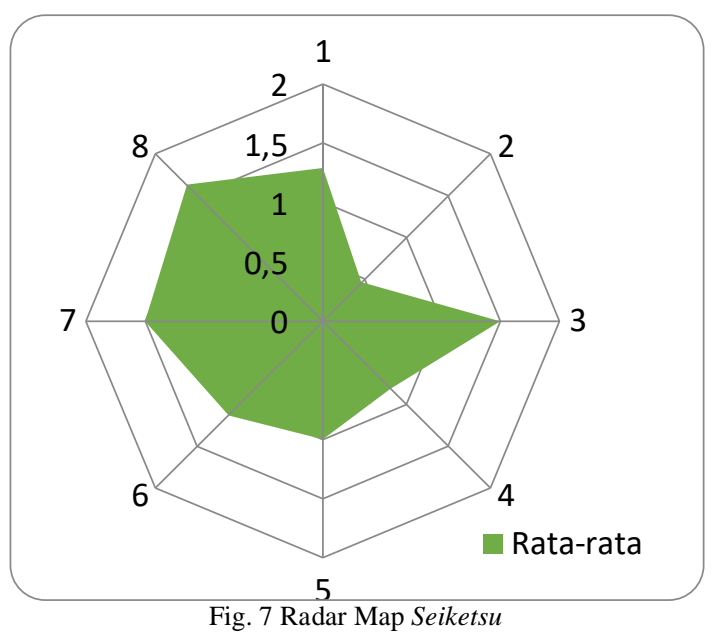

The figures showed that low for the station that is the second station (Tipler and rail Track) with weights-1.33 means the most problematic if seen from the approach of seiketsu tipler and rail station is a track where the conditions were never in the work area neat and clean. This problem will cause workers are getting lazy in implementing hygiene and tidiness work area so that the nature of the production floor in time will be more irregular and materials will be produced also didn't clean so that it will reduce the quality of the product.

\section{E. Shitsuke}

Recap of the questionnaire Shitsuke diagnosis can be seen in Table V.

TABLE V

RECAPITUlation SHITSUKE DiagNOSIS

\begin{tabular}{|c|c|c|c|c|c|c|c|c|c|}
\hline \multicolumn{10}{|c|}{ Shitsuke } \\
\hline \multirow{2}{*}{$\begin{array}{l}\text { State- } \\
\text { ment }\end{array}$} & \multicolumn{8}{|c|}{ Station } & \multirow{2}{*}{$\begin{array}{l}\text { Ave- } \\
\text { rage }\end{array}$} \\
\hline & 1 & 2 & 3 & 4 & 5 & 6 & 7 & 8 & \\
\hline 1 & 2 & 1 & 1,5 & 1,5 & 2 & 1,5 & 2 & 1,67 & 1,65 \\
\hline 2 & 1,33 & 1,33 & 1 & 1,5 & 1,5 & 1 & 1,5 & 1,33 & 1,31 \\
\hline 3 & 2 & 1,33 & 1,5 & 1,5 & 1 & 1,5 & 1,5 & 2 & 1,54 \\
\hline 4 & 2 & 1,67 & 1 & 1,5 & 1,5 & 2 & 1,75 & 1,67 & 1,64 \\
\hline 5 & 2 & 1 & 2 & 2 & 1,5 & 1,5 & 1,5 & 1,67 & 1,65 \\
\hline 6 & 2 & 1 & -1 & 1 & -1 & 1,5 & 1,25 & $\begin{array}{c}- \\
0,33\end{array}$ & 0,55 \\
\hline 7 & 1,33 & 1 & 1,5 & 1 & 1 & 1 & 1,25 & 1 & 1,14 \\
\hline 8 & 1,67 & 1 & 2 & 1 & 1 & 1,5 & 1 & 1,66 & 1,35 \\
\hline $\begin{array}{l}\text { Ava- } \\
\text { rage }\end{array}$ & 1,79 & 1,17 & 1,19 & 1,38 & 1,06 & 1,44 & 1,47 & 1,33 & \\
\hline
\end{tabular}


Shitsuke radar map is shown in Figure 8.

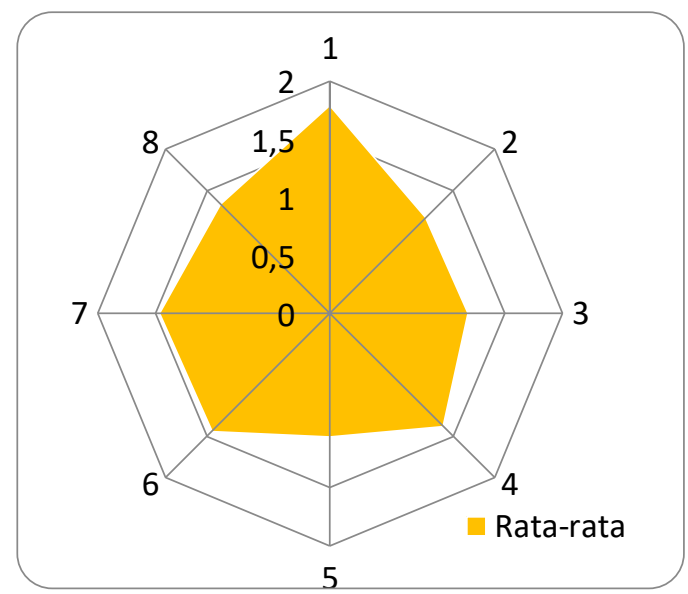

Fig. 8 Radar Map Shitsuke

The figures showed that low for the station that is the fifth station (Clarification) with a weight of-1 means that the most problematic if seen from the approach shitsuke is no shift system for cleanliness. This problem will cause workers do not mean routine hygiene workers hygiene only do if the work area is already very dirty.

\section{CONCLUSIONS}

The conclusion is based on research that has been done is there are things that need to be repaired and must be maintained at the industry specified in the description below.

Things must be maintained:

1) Seiri: Machinery and equipment at each work station is ready for use

2) Seiton: Workers know where the equipment / goods should be stored

3) Seiso: Machinery hygiene maintained and production floor

4) Seiketsu: Tests carried out on machinery and equipment to be always ready to use

5) Shitsuke: Workers understand and familiarize against procedures of $5 \mathrm{~S}$
Things that should be corrected:

1) Seiri: All the machinery or equipment used is not in regular condition

2) Seiton: Finished product that is not laid out neatly

3) Seiso: There is a oil spill or residual material scattered on the floor

4) Seiketsu: The workersare not doing extra cleaning before and after work

5) Shitsuke: The workers are not respectthe customs and regulations in the industry

\section{ACKNOWLEDGMENT}

Special thanks to my students Savudan, Muhammad Akbar, Tuah Affandi for their efforts that have been given in this research. The authors gratefully acknowledge that the present research is supported by Ministry of Research and Technology and Higher Education Republic of Indonesia. The support is under the research grant BP-PTN USU of Year 2016.

\section{REFERENCES}

[1] Mariano Jiménez, "5S Methodology Implementation In The Laboratories Of an Industrial Engineering University School," Universidad de Comillas, Madrid, Spain, 2015.

[2] Zelinski, P.C.. If 5S is good, try 13 S next. Mod. Mach. Shop 77 (9), 12, 2005.

[3] Miroslava Míkva, "Standardization - one of the tools of continuous improvement," Institute of Industrial Engineering and Management, Slovakia, 2016.

[4] Lixia, C., Bo, M., "How to Make 5S as a Culture in Chinese Enterprises," School of Economics and Management, Changchun University of Science and Technology, Department of Industry Management, 2011.

[5] Government of Indonesia Presidential Decree No No 61 Year 2011, National Action Plan For ReducingGreenhouse Gas Emissions.

[6] Minister of Energy and Mineral Resources, 2011, Handbook of Energy and Economic Statistics of Indonesia, 2011.

[7] Hutapea M 2012 Reviewing opportunities for bio-energy and waste to energy development in Indonesia, Ministry of Energy and Minereal Resoruces of Indonesia.

[8] Bedoya ID, Saxena S, Cadavid FJ, Dibble RW, Wissink M 2012Applied Energy 618-629.

[9] Cacua K, Amell A, Cadavid F 2012 Biomass and Bioenergy45(2) 159167.

[10] Tippayawong N, Promwungkwa P, Rerkkriangkrai 2007 Biosystem Engineering98 26-32.

[11] Makareviciene V, Sendzikiene E., Pukalskas S, Rimkus A, Vegneris R 2013 Energy Conversion and Management75 224 - 233.

[12] Tonkunya N, Wongwuttanasatian T 2013 Energy for Sustainable Development $17240-244$.

[13] Nathan SS, Mallikarjuna JM, Ramesh A 2010 Energy Conversion and Management51 1347 - 135 